\title{
A role for pre-mNK cells in tumor progression
}

\author{
Carolyn Rosinsky ${ }^{1,2}$ and Paul Andrew Antony ${ }^{2,3,4^{*}}$ (i)
}

\begin{abstract}
The innate and adaptive immune systems have evolved together to fight infection and cancerous tissues. The innate immune system emerges first with the adaptive immune system following, both ostensibly being bridged by dendritic cells (DC). Recently cells have emerged that possess characteristics of both innate and adaptive immune cell qualities, termed interferon-producing killer dendritic cells (IKDCs). These cells have an indistinct origin that is not well understood. They appear to have more NK cell attributes than DC but purportedly can regulate the immune system similar to immunoregulatory NK cells. Because of this, they have been renamed pre-mNK cells (pre-mature NK cells). We argue in this commentary that pre-mNK cells may contribute to cancer recurrence.
\end{abstract}

Keywords: Pre-mNK cells, IKDC, CD4 ${ }^{+}$T cells, Melanoma, PD-L1

\section{Introduction}

Pre-mature Natural Killer cells (pre-mNK) are murine hybrid cells with characteristics of both NK cells and $\mathrm{DC}$, defined by markers $\mathrm{CD} 11 \mathrm{c}^{+} \mathrm{CD} 49 \mathrm{~b}^{+} \mathrm{B} 220^{+} \mathrm{NK} 1.1$ ${ }^{+} \mathrm{NKG} 2 \mathrm{D}^{+} \mathrm{GR}-1^{-}$and expressing MHC class II upon activation [1-4] (Fig. 1). Originally called IKDC, these cells were first characterized in $2006[1,5,6]$, but since then have been recognized to more closely resemble NK cells rather than DC or plasmacytoid DCs (pDCs) [7, 8]. Specifically, pre-mNK cells resemble an immature NK, before the cell begins to express CD27, and have classical attributes of cellular immaturity such as immature cell morphology, expression of Ly108, and low amounts of CD43. These cells also are dependent on the Id-2 transcription factor, which has been shown to inhibit pDC differentiation [9]. Once these cells begin to express CD27, they stop expressing the pre-mNK marker B220 and their function changes, commonly from that of a pre-mNK cell to that of a mature NK (mNK) cell $[6-8,10]$. Little is known about the formation or differentiation of these cells, but their development is

\footnotetext{
*Correspondence: pantony@som.umaryland.edu

Carolyn Rosinsky first author.

${ }^{2}$ Department of Pathology, University of Maryland School of Medicine, Baltimore, MD 21201, USA

${ }^{3}$ Department of Microbiology and Immunology, University of Maryland School of Medicine, 10 South Pine Street, 734D MSTF, Baltimore, MD 21201, USA

Full list of author information is available at the end of the article
}

IL-15 dependent [2, 4, 11], and appears to depend on their environment in which they reside and become activated $[6,12]$. Below we discuss their implications in tolerance to tumors both in mice and humans.

\section{Murine pre-mNK cells}

Initially, murine pre-mNK cells were described in mice to have anti-tumor properties [5, 6]. However, subsequent studies, including our own data, have shown that depletion of NK1.1 $1^{+}$cells leads to enhanced tumor rejection, viral clearance, and decreased exhaustion of $\mathrm{T}$ cells [13-19]. Surprisingly most of the studies that depleted $\mathrm{NK} 1.1^{+}$cells failed to show that pre-mNK cells were also being depleted [11]. These findings seem to contradict the anti-tumor, cytotoxic role of these cells. One recent study showed that activated pre-mNK cells prevented autoimmunity through PD-L1 and IL-10 [20]. Therefore, it seems that the natural predilection for pre-mNK cells is to suppress autoimmunity. We hypothesize that this attribute of pre-mNK cells contributes to tumor recurrence.

The role of pre-mNK cells in the context of immunotherapy using adoptive cell transfer (ACT) of T cells has not been studied. Pre-mNK cells have mainly been used in isolation as tumor killers or in the context of non-self tumor-antigens such as OVA. These non-self antigens activate high affinity $\mathrm{T}$ cells that were not educated for OVA in the thymus, and as a result, $\mathrm{T}_{\text {reg }}$ cells to OVA 
Murine pre-mNK cell

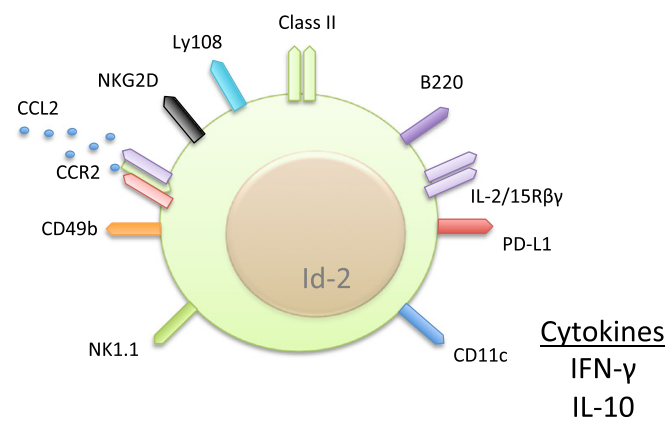

Human CD56 brightHLA-DR+ cell

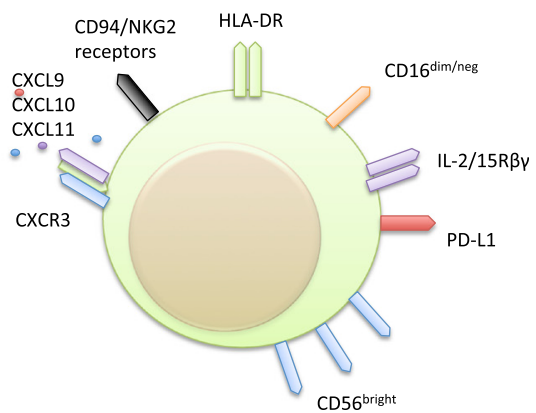

Fig. 1 Comparison between the immune-related molecules expressed on murine pre-mNK cells and human CD56 ${ }^{\text {bright }}$ HLA-DR ${ }^{+}$NK cells. Murine pre-mNK cells classically express CD11 $c^{\text {lo } C D 49 b B 220 N K 1.1}$ and are GR-1 ${ }^{\text {neg }}$ in C57BL6/mice, but lack NK1.1 in other strains. Pre-mNK cells also express NKG2D and respond to the chemokine CCL2 due to expression of CCR2, making them apt for migrating to tumor sites. Upon licensing by tumor cells, pre-mNK cells express class II and other immune related molecules. The Id-2 transcription factor is prevalent in pre-mNK cells showing that they are more NK cell-like than DC. Both murine and human CD56 bright HLA-DR ${ }^{+} N K$ cells express the IL-2/LL-15R $\beta \gamma$, making them responsive to these cytokines in different contexts. Human CD56 bright HLA-DR ${ }^{+}$NK cells express CD56 at high levels, HLA-DR, and CD94/NKG2 receptors, and low to no amounts CD16. They are CXCR3 expressing cells making them able to migrate to secondary lymphatic tissues or places of inflammation. Both murine and humans cells may also express PD-L1 in different environmental conditions, and both can make IFN- $\gamma$ and IL-10 in varying amounts, again depending on their environment. By no means are these molecules listed complete or absolute and further research is needed to clarify the roles of each on these cells

do not exist [21]. This may confound the natural activity of pre-mNK cells which is to suppress tumor-antigens that are also self-antigens.

Previously, we have shown that $\mathrm{CD} 4^{+} \mathrm{T}$ cells specific for a tumor-associated self-antigen (TAA) called tyrosinaserelated protein 1 (TRP-1), a melanoma differentiation antigen (MDA), can treat large established tumors by direct killing of cancerous cells [16]. We found that lymphopenia (either induced before adoptive transfer or naturally occurring in $\mathrm{RAG}^{-/-}$mice) enhanced rejection of tumors through loss of regulatory elements such as $\mathrm{T}_{\text {reg }}$ cells and MDSCs [22] or through increased homeostatic cytokines that could potentially help $\mathrm{T}$ cells attack tumors better [23, 24]. Nevertheless, about $50 \%$ of the tumors would recur locally $[23,24]$. Surprisingly, cancer recurrence was diminished considerably when $\mathrm{NK}_{1} .1^{+}$cells were depleted with PK-136 depleting antibodies. In addition, depletion of $\mathrm{NK} 1.1^{+}$cells increased autoimmune vitiligo, serum inflammatory cytokines, and chemokines [11]. This was thought to be due to the absence of NK cell "cytokine sinks," [22] thus enhancing the cytotoxicity of the $\mathrm{CD} 4^{+} \mathrm{T}$ cells through increased availability of IL-2 and possibly IL-15. However, depletion of NK cells with NK cell-specific antibody, called asialo-GM1, failed to fully duplicate the results from experiments employing NK1.1 $1^{+}$cell depletion [11]. Furthermore, we showed that $\mathrm{B}_{220^{+}}$cell depletion but not asialo-GM1 ${ }^{+}$cell depletion was similar to the depletion of $\mathrm{NK} 1.1^{+}$cells, suggesting that $\mathrm{B} 220^{+} \mathrm{NK} 1.1^{+}$pre-mNK cells were playing a role in dampening the $\mathrm{CD}^{+}$anti-tumor response in our preclinical model of melanoma [11].
These data made us question the purported role of pre-mNK cells in cancer biology.

Since 2006, the role of pre-mNK in the tumor setting has been equivocal. Taieb et al. first described that treating melanoma with Imatinib and IL-2 resulted in pre-mNKs expanding in the spleen, producing copious IFN- $\gamma$, and killing tumor cells via TRAIL [5]. Although the tumor microenvironment affects the function of pre-mNK [8], only our group studied pre$\mathrm{mNK}$ cells without ex vivo pre-activation, calling into question the anti-tumor role of pre-mNK cells in the natural course of the disease [11]. We suggest, as others have implicated, that pre-mNK cells must be licensed by tumor cells through NKG2D or other ligands to become activated $[3,21]$. This leads to their maturation into functional APCs through upregulation of MHC class II and other receptors, and their migration into draining lymph nodes where they present tumor-self antigens to self-reactive $T$ cells which are tolerized or programmed to become $\mathrm{T}_{\text {reg }}$ cells rather than activated effector cells. Experiments by others using blocking antibodies to NKG2D decreased the activation of OTII cells by OVA expressing B16-Rae1 cells [21], suggesting that if licensing cannot occur by tumor cells, pre-mNK cells cannot interact with T cells through MHC class II. Licensing occurs to allow pre-mNK cells to kill tumor cells initially so that they may acquire tumor antigen for presentation, occurring in less than $48-72 \mathrm{~h}$ as shown by migration experiments [3]. This is temporary and results only in delay of tumor growth [3]. We suggest that this licensing could be mistaken for tumor killing. 
Although pre-mNK cells were first described for their role in anti-tumor immunity, they have been described as controlling tolerance to self-antigens [20]. These cells prevent autoimmunity or reduce the severity of autoimmune conditions such as experimental autoimmune encephalitis (EAE) [4, 17]. Melanoma has also been shown to license $\mathrm{NK} 1.1^{+} \mathrm{B} 220^{+} \mathrm{CD} 11 \mathrm{c}^{+} \mathrm{MHC}$ class $\mathrm{II}^{+}$ pre-mNK cells to present tumor antigens [3, 21]. PremNK cells also express the inhibitory PD-1 ligand (PD-L1) [12, 20, 21] and can make the immunosuppressive cytokine, IL-10 [20]. PD-L1 has clearly been shown in pre-clinical [25-28] and clinical scenarios to inhibit tumor immunity through adaptive resistance mechanisms $[29,30]$ as well as to be involved in controlling chronic infections and autoimmunity [31-35]. Thus premNK cells expressing PD-L1 could potentially suppress immunity to cancer, like cancer cells themselves. Because melanoma can expresses TRP-1, a melanocyte differentiation antigen expressed in the skin that is targeted by our TRP-1 specific $\mathrm{CD}^{+} \mathrm{T}$ cells, autoimmunity can ensue. Therefore, pre-mNK cells might be involved in tolerance rather than immunity during an immune response to melanoma. This is demonstrated in our recent work showing that autoimmune vitiligo is increased in tumor-bearing mice treated with $\mathrm{CD} 4^{+} \mathrm{T}$ cells specific for TRP-1 and antibodies to deplete NK1.1 $1^{+}$cells [11].

Like NK cells, pre-mNK cells are IL-15 dependent [1]. It has been shown that production of hIL-15 by in vivo gene transfer in mice increases pre-mNK cell numbers and function [36]. On the contrary, IL-15 ${ }^{-/-} \mathrm{RAG}^{-/-}$and IL-2R ${ }^{-1-} \mathrm{RAG}^{-/-}$mice both lack NK and pre-mNK cells $[4,7,11]$. Consistent with this, we have shown that tumor rejection is enhanced in $\mathrm{IL}-15^{-1-} \mathrm{RAG}^{-1-}$ mice and that recurrence of melanoma is less when compared to IL-15 wild type controls [11]. In line with this data, it has been shown that pre-mNK cells are low in autoimmune prone NOD mice, which are susceptible to diabetes due to genetic mutations linked to the distal end of chromosome 7 [37]. If the distal end of chromosome 7 is modified to express WT genes as in NOD-Lc7 mice, they are not prone to diabetes, and have restored numbers of pre-mNK cells [1]. This suggests that the natural tendency of pre-mNK cells is to cause suppression rather than immunity in vivo.

Pre-mNK cell function modulates over the course of an immune response. After stimulation, presumably through NKG2D and other ligands, pre-mNK cells first acquire lytic activity, signaling through classical NK receptors such as NKG2D, and killing through NKG2D and TRAIL $[3,6,10]$. They then produce IFN- $\gamma$, and increase expression of MHC-II and migrate via chemokine receptors to the secondary lymphatic tissue $[6,10]$. In the tumor microenvironment, direct contact with the tumor cell provides this stimulation, leading not only to
MHC-II expression and IFN- $\gamma$ production, but also to IFN- $\gamma$-induced PD-L1 expression [8, 12, 21, 30]. We suggest that this adaptive immune response induces exhaustion and increases $T_{\text {reg }}$ cells, suppressing $\mathrm{T}$ cell function. Because the tumor cell itself licenses pre-mNK cells for antigen presentation, the antigens encountered are likely to be self-antigens $[3,21]$. Thus, in untreated cancer, unmanipulated pre-mNK cells may act to protect the host by dampening the immune response - beneficial in autoimmunity, but detrimental in cancer or chronic infections [20]. However, experimentally manipulated pre-mNK cells, those which are mostly studied up to this point, may actually activate the immune response because treatment-induced cellular trauma makes more DAMPs available, thus confounding their natural role $[1,3-7,21]$.

\section{Human pre-mNK cells}

The closest pre-mNK analog in humans is the CD56 bright NK cell [38] or the HLA-DR ${ }^{+}$NK cell, which is a subset of CD56 ${ }^{\text {bright }}$ NK cells [39]. Here, we will refer to the human equivalent as CD56 $6^{\text {bright }} \mathrm{HLA}-\mathrm{DR}^{+} \mathrm{NK}$ cells because these cells expand only from HLA-DR ${ }^{+}$NK cell populations and can present antigen [39]. However, we will also refer to CD56 ${ }^{\text {bright }}$ cells alone when discussing literature pertaining only to them and try to draw out similarities between ${\text { CD } 56^{\text {bright }}}$ CD56 $6^{\text {bright }}$ HLA-DR $^{+}$NK cells, and mouse pre-mNK cells. Our goal is to suggest that premNK cells in humans are CD56 $6^{\text {bright }} \mathrm{HLA}^{-\mathrm{DR}^{+}} \mathrm{NK}$ cells.

Like pre-mNK cells, CD56 ${ }^{\text {bright }}$ NK cells are recognized as an immunoregulatory NK subset in humans [40-42], and are defined by the markers $\mathrm{CD}^{-} \mathrm{CD} 56$ ${ }^{+}$CD16 ${ }^{\text {dim }}$ HLA-DR ${ }^{+}[38,39,42-45]$ (Fig. 1). Like premNK cells they represent a small subset of total NK cells, approximately less than $10 \%$ of $\mathrm{CD}^{2} 6^{+}$cells [42]. In their regulatory role, they lyse $\mathrm{CD} 4^{+} \mathrm{T}$ cells via TRAIL and NKG2D, and secrete large amounts of IFN- $\gamma$ and regulatory cytokines $[41,45,46]$. Like pre-mNK cells, CD56 ${ }^{\text {bright }}$ NK cells are dependent on IL-15 for development and activation [42-44], and are implicated in controlling autoimmunity and mediating the immune response to cancer and viral infections. In non-pathologic physiology, CD56 ${ }^{\text {bright }}$ NK cells maintain fetal tolerance by inhibiting Th-17-mediated immune responses at the maternal-fetal interface [47].

HLA-DR $^{+}$NK cells also expand to IL-15 and high doses of IL-2 [39]. However, these types of experimental systems used to study these cells in vitro, we would argue, can be highly non-physiologic and may drive HLA-DR ${ }^{+}$NK cells to a cytotoxic phenotype, leading to large amounts of IFN- $\gamma$ secretion. However, their physiological role in vivo without external activation may involve tolerance mechanisms as these cells are seen at 
sites of inflammation, cancer, and at the maternal-fetal interface [47-52].

Solid tumors have large populations of CD56 $6^{\text {bright }}$ NK cells at the primary tumor bed and at metastases, and similarly to pre-mNK, they expand following treatment [48-52]. As tumors progress or metastasize, CD56 ${ }^{\text {bright }}$ NK cells remain present in the primary bed, at the metastases, and in lymph tissue, but lose function or become inactive despite high expression levels of perforin and HLA-DR $[50,53,54]$. These cells we hypothesize are CD56 ${ }^{+}$HLA-DR ${ }^{+}$NK cells mentioned above that have induced tolerance to tumor.

CD56 ${ }^{\text {bright }}$ NK cells have lytic activity via TRAIL, and when activated, upregulate HLA-DR and IFN- $\gamma$ production to present antigen and modulate the immune response, either productively or pathologically [55]. This may be similar to pre-mNK cell activation through NKG2D ligands on murine tumors, allowing them to present antigen once it is acquired [3]. Although they can be lytic, it also has been shown that in both the viral and the autoimmune setting that CD56 ${ }^{\text {bright }}$ NK cells control $\mathrm{CD} 4^{+} \mathrm{T}$ cell activity by expressing high levels of CD39/73 and CD38, using adenosine as a modulator of $\mathrm{T}$ cell activity. Stelma et al. report that after HBV treatment and improved ALT, the host's CD56 ${ }^{\text {bright }}$ NK cells express high levels of $\mathrm{CD} 38$, attenuating the chronic pathologic immune response [55]. Morandi et al. report that CD38 inhibition increases Juvenile Idiopathic Arthritis (JIA) severity, while the CD38 enzyme expressed by CD56 $6^{\text {bright }}$ NK cells in patients with active JIA has attenuated function [56].

\section{Conclusion}

CD56 ${ }^{\text {bright }}$ HLA-DR ${ }^{+}$immunoregulatory NK cells are potentially the human analog of the contentious murine pre-mNK cell. These highly proliferative cells, though a small population in both species, can readily expand to regulate the immune response, acting through direct cytolysis, cytokines, and metabolic signals, and acting as antigen-presenting cells with the capability to activate or terminate an immune response. These cells in human and mouse clearly stifle immune activity in autoimmunity and pregnancy. Their role in chronic pathology is more complex. Acting through cytolysis and/or antigenpresentation, CD56 ${ }^{\text {bright }} \mathrm{HLA}^{-\mathrm{DR}^{+}} \mathrm{NK}$ or pre-mNK cells may dampen the response to chronic low-level stimulation or self-antigen, for instance during established melanoma, but they activate a response under acute conditions of treatment-induced DAMPs, high-level PAMP stimulation, or high doses of $\gamma_{c}$-cytokines such as IL-2 or IL-15. Thus, pre-mNK or CD56 ${ }^{\text {bright }}$ HLA-DR $^{+}$ NK cells have the potential to be exploited therapeutically, but their opposing roles in differing immune environmental milieus must be taken into consideration.
CD56 ${ }^{\text {bright }}$ cells and murine counterpart pre-mNK cells represent potential targets for immunotherapies, whether to suppress the immune system to prevent autoimmune diseases, or to enhance the immune system to treat cancer. It is clear that more research is needed to fully elucidate the role of these cells during an immune response in human disease.

\section{Abbreviations \\ ACT: Adoptive cell transfer; DAMPs: Damage associated molecular patterns; DC: Dendritic cell; IDO: Indoleamine-2,3-deoxygenase; IL: Interleukin; IKDC: Interferon killer dendritic cell; INF-ү: Interferon $\gamma$; NK cell: Natural killer cell; PAMPs: Pathogen associated molecular patterns; PD-1: Programmed cell death protein 1; PD-L1: Programmed death ligand 1; PDC: Plasmacytoid Dendritic Cell; Pre-mNK cells: Pre-mature natural killer cells; TLR: Toll-like receptors; $T_{\text {reg: }}$ Regulatory T cells; TRP-1: Tyrosinase related protein 1.}

\section{Competing interests}

The authors declare that they have no competing interests.

\section{Authors' contributions}

"PAA conceived of the study, and CR and PAA participated in its design and coordination. CR and PAA both helped to draft the manuscript and edited the final version. CR and PAA read and approved the final manuscript."

\section{Acknowledgment}

This work was funded by the American Cancer Society, Research Scholars Grant, Award number, 125472RSG-14-054-01-LIB.

\section{Author details}

${ }^{1}$ Program in Molecular Medicine, University of Maryland School of Medicine, Baltimore, MD 21201, USA. ²Department of Pathology, University of Maryland School of Medicine, Baltimore, MD 21201, USA. ${ }^{3}$ Department of Microbiology and Immunology, University of Maryland School of Medicine, 10 South Pine Street, 734D MSTF, Baltimore, MD 21201, USA. ${ }^{4}$ Tumor Immunology and Immunotherapy Program, University of Maryland Cancer Center, Baltimore, MD 21201, USA.

Received: 6 November 2015 Accepted: 19 February 2016 Published online: 15 March 2016

\section{References}

1. Shortman K, Villadangos JA. Is it a DC, is it an NK? No, it's an IKDC. Nat Med. 2006;12:167-8.

2. Vosshenrich CA et al. CD11cloB220+ interferon-producing killer dendritic cells are activated natural killer cells. J Exp Med. 2007;204:2569-78.

3. Himoudi $\mathrm{N}$ et al. Migratory and antigen presentation functions of IFNproducing killer dendritic cells. Cancer Res. 2009;69:6598-606.

4. Guimont-Desrochers F, Lesage S. Revisiting the Prominent Anti-Tumoral Potential of Pre-mNK Cells. Front Immunol. 2013;4:446.

5. Taieb J et al. A novel dendritic cell subset involved in tumor immunosurveillance. Nat Med. 2006;12:214-9.

6. Chan CW et al. Interferon-producing killer dendritic cells provide a link between innate and adaptive immunity. Nat Med. 2006;12:207-13.

7. Guimont-Desrochers $F$ et al. Redefining interferon-producing killer dendritic cells as a novel intermediate in NK-cell differentiation. Blood. 2012;119: 4349-57.

8. Zitvogel L, Housseau F. IKDCs or B220+ NK cells are pre-mNK cells. Blood. 2012;119:4345-6.

9. Wu L, Liu YJ. Development of dendritic-cell lineages. Immunity. 2007;26: $741-50$.

10. Himoudi $\mathrm{N}$ et al. Bone marrow-derived IFN-producing killer dendritic cells account for the tumoricidal activity of unpulsed dendritic cells. J Immunol. 2008;181:6654-63.

11. Wilson KA, Goding SR, Neely HR, Harris KM, Antony PA. Depletion of B220 +NK1.1+ cells enhances the rejection of established melanoma by tumorspecific CD4+ T cells. Oncoimmunology. 2015;4(8):e1019196.

12. Pletneva $\mathrm{M}$ et al. IFN-producing killer dendritic cells are antigen-presenting cells endowed with T-cell cross-priming capacity. Cancer Res. 2009;69:6607-14. 
13. Cook KD, Whitmire JK. The depletion of NK cells prevents T cell exhaustion to efficiently control disseminating virus infection. J Immunol. 2013;190:641-9.

14. Waggoner SN, Cornberg M, Selin LK, Welsh RM. Natural killer cells act as rheostats modulating antiviral T cells. Nature. 2012;481:394-8.

15. Tian Z, Gershwin ME, Zhang C. Regulatory NK cells in autoimmune disease. J Autoimmun. 2012;39:206-15.

16. Xie $Y$ et al. Naive tumor-specific CD4(+) T cells differentiated in vivo eradicate established melanoma. J Exp Med. 2010;207:651-67.

17. Noval Rivas $M$ et al. NK cell regulation of CD4 T cell-mediated graft-versushost disease. J Immunol. 2010;184:6790-8.

18. Perona-Wright $\mathrm{G}$ et al. Systemic but not local infections elicit immunosuppressive IL-10 production by natural killer cells. Cell Host Microbe. 2009;6:503-12.

19. Vivier E, Ugolini S. Regulatory natural killer cells: new players in the IL-10 anti-inflammatory response. Cell Host Microbe. 2009;6:493-5.

20. Huarte E et al. Tolerogen-induced interferon-producing killer dendritic cells (IKDCs) protect against EAE. J Autoimmun. 2011;37:328-41.

21. Terme $M$ et al. The dendritic cell-like functions of IFN-producing killer dendritic cells reside in the CD11b+ subset and are licensed by tumor cells. Cancer Res. 2009;69:6590-7.

22. Gattinoni $L$ et al. Removal of homeostatic cytokine sinks by lymphodepletion enhances the efficacy of adoptively transferred tumorspecific CD8+ T cells. J Exp Med. 2005;202:907-12.

23. Restifo NP, Dudley ME, Rosenberg SA. Adoptive immunotherapy for cancer: harnessing the T cell response. Nat Rev Immunol. 2012;12:269-81.

24. Gattinoni L, Powell Jr DJ, Rosenberg SA, Restifo NP. Adoptive immunotherapy for cancer: building on success. Nat Rev Immunol. 2006;6: 383-93

25. Penaloza-MacMaster $P$ et al. Interplay between regulatory $T$ cells and PD-1 in modulating $T$ cell exhaustion and viral control during chronic LCMY infection. J Exp Med. 2014;211:1905-18.

26. Goding SR et al. Restoring immune function of tumor-specific CD4+ T cells during recurrence of melanoma. J Immunol. 2013;190:4899-909.

27. Topalian SL, Drake CG, Pardoll DM. Targeting the PD-1/B7-H1(PD-L1) pathway to activate anti-tumor immunity. Curr Opin Immunol. 2012;24:207-12.

28. Butler NS et al. Therapeutic blockade of PD-L1 and LAG-3 rapidly clears established blood-stage Plasmodium infection. Nat Immunol. 2012;13:188-95.

29. Tumeh PC et al. PD-1 blockade induces responses by inhibiting adaptive immune resistance. Nature. 2014;515:568-71.

30. Taube JM et al. Colocalization of inflammatory response with B7-h1 expression in human melanocytic lesions supports an adaptive resistance mechanism of immune escape. Sci Transl Med. 2012:4:127ra137.

31. Kasagi S, Kawano S, Kumagai S. PD-1 and autoimmunity. Crit Rev Immunol. 2011;31:265-95.

32. Okazaki T et al. PD-1 and LAG-3 inhibitory co-receptors act synergistically to prevent autoimmunity in mice. J Exp Med. 2011;208:395-407.

33. Fife BT, Pauken KE. The role of the PD-1 pathway in autoimmunity and peripheral tolerance. Ann N Y Acad Sci. 2011;1217:45-59.

34. Francisco LM, Sage PT, Sharpe AH. The PD-1 pathway in tolerance and autoimmunity. Immunol Rev. 2010;236:219-42.

35. Okazaki T, Wang J. PD-1/PD-L pathway and autoimmunity. Autoimmunity. 2005;38:353-7.

36. Arina $\mathrm{A}$ et al. Interleukin-15 liver gene transfer increases the number and function of IKDCs and NK cells. Gene Ther. 2008:15:473-83.

37. Guimont-Desrochers F, Cappello ZJ, Chagnon M, McDuffie M, Lesage S. Cutting edge: genetic characterization of IFN-producing killer dendritic cells. J Immunol. 2009;182:5193-7.

38. Chaput $\mathrm{N}$ et al. Phase I clinical trial combining imatinib mesylate and IL-2: HLA-DR NK cell levels correlate with disease outcome. Oncoimmunology. 2013;2:e23080

39. Evans $\mathrm{JH}$ et al. A distinct subset of human NK cells expressing HLA-DR expand in response to $\mathrm{IL}-2$ and can aid immune responses to BCG. Eur J Immunol. 2011:41:1924-33.

40. Martin JF, Perry JS, Jakhete NR, Wang X, Bielekova B. An IL-2 paradox: blocking CD25 on T cells induces IL-2-driven activation of CD56(bright) NK cells. J Immunol. 2010;185:1311-20.

41. Nielsen N, Odum N, Urso B, Lanier LL, Spee P. Cytotoxicity of CD56(bright) NK cells towards autologous activated CD4+ T cells is mediated through NKG2D, LFA-1 and TRAIL and dampened via CD94/NKG2A. PLoS One. 2012; 7:e31959.
42. Cooper MA et al. Human natural killer cells: a unique innate immunoregulatory role for the CD56(bright) subset. Blood. 2001:97:3146-51.

43. Fehniger TA, Caligiuri MA. Interleukin 15: biology and relevance to human disease. Blood. 2001;97:14-32.

44. Mrozek E, Anderson P, Caligiuri MA. Role of interleukin-15 in the development of human CD56+ natural killer cells from CD34+ hematopoietic progenitor cells. Blood. 1996;87:2632-40.

45. Pautier $P$ et al. Phase I clinical trial combining imatinib mesylate and IL-2 in refractory cancer patients: IL-2 interferes with the pharmacokinetics of imatinib mesylate. Oncoimmunology. 2013;2:e23079.

46. Mirjacic Martinovic KM et al. Decreased expression of NKG2D, NKp46, DNAM-1 receptors, and intracellular perforin and STAT-1 effector molecules in NK cells and their dim and bright subsets in metastatic melanoma patients. Melanoma Res. 2014;24:295-304.

47. Fu B et al. Natural killer cells promote immune tolerance by regulating inflammatory TH17 cells at the human maternal-fetal interface. Proc Nat Acad Sci U S A. 2013;110:E231-40.

48. Rusakiewicz $\mathrm{S}$ et al. Immune infiltrates are prognostic factors in localized gastrointestinal stromal tumors. Cancer Res. 2013;73:3499-510.

49. Levi I et al. Characterization of tumor infiltrating natural killer cell subset. Oncotarget. 2015;6:13835-43

50. Riley $\mathrm{CH}$ et al. Expansion of circulating CD56bright natural killer cells in patients with JAK2-positive chronic myeloproliferative neoplasms during treatment with interferon-alpha. Eur J Haematol. 2015:94:227-34.

51. Vuletic $A$ et al. Distribution of several activating and inhibitory receptors on CD3(-)CD56(+) NK cells in regional lymph nodes of melanoma patients. J Surg Res. 2013;183:860-8.

52. Koo KC et al. Reduction of the CD16(-)CD56bright NK cell subset precedes NK cell dysfunction in prostate cancer. PLoS One. 2013;8:e78049.

53. Messaoudene M et al. Mature cytotoxic CD56(bright)/CD16(+) natural killer cells can infiltrate lymph nodes adjacent to metastatic melanoma. Cancer Res. 2014;74:81-92.

54. Carrega P et al. CD56(bright)perforin(low) noncytotoxic human NK cells are abundant in both healthy and neoplastic solid tissues and recirculate to secondary lymphoid organs via afferent lymph. J Immunol. 2014;192:3805-15.

55. Stelma F et al. Natural Killer Cell Characteristics in Patients With Chronic Hepatitis B Virus (HBV) Infection Are Associated With HBV Surface Antigen Clearance After Combination Treatment With Pegylated Interferon Alfa-2a and Adefovir. J Infect Dis. 2015;212:1042-51

56. Morandi F et al. CD56brightCD16- NK Cells Produce Adenosine through a CD38-Mediated Pathway and Act as Regulatory Cells Inhibiting Autologous CD4+ T Cell Proliferation. J Immunol. 2015:195:965-72.

\section{Submit your next manuscript to BioMed Central and we will help you at every step:}

- We accept pre-submission inquiries

- Our selector tool helps you to find the most relevant journal

- We provide round the clock customer support

- Convenient online submission

- Thorough peer review

- Inclusion in PubMed and all major indexing services

- Maximum visibility for your research

Submit your manuscript at www.biomedcentral.com/submit 